\title{
The cyclopean eye vs. the sighting-dominant eye as the center of visual direction
}

\author{
HIROSHI ONO \\ York University, Downsview, Ontario, Canada \\ and \\ RAPHAEL BARBEITO \\ University of Waterloo, Waterloo, Ontario, Canada
}

\begin{abstract}
In three experiments, competing hypotheses concerning the center of visual direction were examined with the stimuli used in the Card test which requires a subject to position the card with a hole so that a target can be seen. Each experiment used six right- and six left-sightingeye subjects. In Experiment 1, the aperture and the target were collinear with the sighting eye. The mean apparent locations of the aperture when the target was fixated, and of the target when the aperture was fixated, were consistent with only the cyclopean-eye hypothesis; that is, the $95 \%$ confidence intervals of these means contained the predicted values from the cyclopeaneye hypothesis but not those from the sighting-eye hypothesis. In Experiment 2, subjects moved the card from the side of the nonsighting eye, and in $88 \%$ of the trials it was stopped when the nonsighting eye viewed the target. In Experiment 3, the target was viewed through the aperture with both the sighting and nonsighting eye in six different stimulus arrangements. The $95 \%$ confidence intervals of all 12 mean apparent locations of the targets contained the predicted values from the cyclopean-eye hypothesis but none of those from the sighting-eye hypothesis. These results are compatible with the cyclopean-eye hypothesis, and we therefore conclude that the sighting eye is not the center of visual direction.
\end{abstract}

An important premise in the study of visual direction is that there is a center or origin for judgments of visual direction. This center point is posited because visual direction deals with angles and thus requires an origin like that of polar coordinates in plane geometry. There are two competing hypotheses as to where the center is located. One hypothesis postulates that it is located midway between the two eyes (Fry, 1950; Hering, 1868/1977, 1879/1942; Le Conte, 1881). This midway point has many names: the cyclopean eye, the visual egocenter, the binoculus, the projection center, and the center for visual direction. Another hypothesis postulates that it is located in one eye (Parson, 1924; Porac \& Coren, 1981; Rubin \& Walls, 1969; Sheard, 1926; Walls, 1951). This second point is called the sighting eye, the sightingdominant eye, or simply the dominant eye. (Henceforth, we will use the term "sighting eye" to mean

This research was supported by Grant A0296 from the Natural Sciences and Engineering Research Council of Canada. The authors wish to thank their many colleagues in experimental psychology at York University for helpful comments on an earlier version of this paper. Requests for reprints should be sent to Hiroshi Ono, Department of Psychology, 213 Behavioral Sciences Building, York University, 4700 Keele Street, Downsview, Ontario M3J 1P3, Canada. the eye preferred for viewing in a sighting test. This term will be maintained even if the subject uses the nonpreferred eye, as in Experiments 2 and 3. We concur with a reviewer of this paper that the term "dominant eye" carries excess meaning that leads to confusion.)

While the implications of these two hypotheses differ, the hypotheses themselves have seldom been considered as competing ones. In fact, an eccentrically located cyclopean eye is sometimes used interchangeably with the sighting eye (e.g., Charnwood, 1949, 1965; Collinge, 1979; Pickwell, 1972). Such treatment may be justified because the cyclopean eye is not always centrally located, and the cyclopean and the sighting eye are related. Specifically, the location of the cyclopean eye covaries with the sighting eye (Barbeito, 1980, 1981; Francis \& Harwood, 1951; Roelofs, 1959); thus, visual direction covaries with the sighting eye (Barbeito, 1980, 1981; Ogle, 1962, p. 414) and with the eccentricity of the cyclopean eye (Barbeito \& Ono, 1979; Ono, Wilkinson, Muter, \& Mitson, 1972). In spite of these associations, predictions from the two hypotheses can differ. For example, Barbeito (1981) predicted and found that when a subject receives no feedback about the location of the sighting "aperture" relative to the target in the Card test (with the aperture covered), the aper- 
ture is placed in line with the cyclopean eye rather than with the sighting eye.

In the present study, the two hypotheses were evaluated by examining the perceived visual direction of the stimuli used in a sighting test. In Experiment 1, predictions from each hypothesis concerning the perception of stimuli collinear with the sighting eye were compared with the measured visual direction of the stimuli. In Experiment 2, the sighting test was modified, and the frequency of sighting with the nonsighting eye was determined. In Experiment 3, predictions from each hypothesis concerning stimuli collinear with either the sighting or the nonsighting eye were compared with the measured visual direction.

\section{EXPERIMENT 1}

The stimulus situation that a subject would view in the Card test was provided, and visual directions of the target and the aperture were determined with the aperture positioned so that the sighting eye could view the target. (The Card test consists of asking the subject to sight the target through a hole in the middle of the card.) Since the cyclopean-eye hypothesis states that the visual direction produced by a given retinal stimulation depends on the angular positions of both eyes, it was important to specify whether the subject was fixating the aperture or the target. Thus, we determined the apparent locations of the stimuli during both of these fixations.

The predictions from the two hypotheses (which follow below) may appear complicated because of their detail, but their conceptual bases are actually quite simple. All predictions are based on the idea that visual directions: (1) have an origin or center; and (2) are determined by the locations of the retinal images and the directions of the visual axes. The first variable, that is, retinal image location, is also known as the "local sign" or the "signal from the imageretina system," and the second variable, that is, the direction of the visual axes, as the "angular eye position" or "signal from the eye-head system." The predictions from the two hypotheses are based upon the different centers of visual direction that each assumes, but otherwise the principles applied to the two hypotheses are the same.

The predictions from both hypotheses follow from the principle of visual direction, which states that: An object that stimulates the center of a fovea will be seen on a line passing through the center of visual direction and the intersection of the two visual axes (see Howard, 1982; Ono, 1979). [A concise statement of this principle can be made if the line is labeled. Wells (1792) labeled it the common axis and stated that objects in the visual axis appear in the common axis.] These predictions are illustrated in Figure 1. Both hypotheses predict apparent locations that are veridical for an object on the intersection of the visual axes. However, they predict different apparent locations for an object in front of or behind the intersection, and this difference is a function of the different locations of the center of visual direction.

Figures $1 \mathrm{a}$ and $1 \mathrm{~b}$ illustrate that the nonfixated stimulus is seen to be collinear with the fixation point

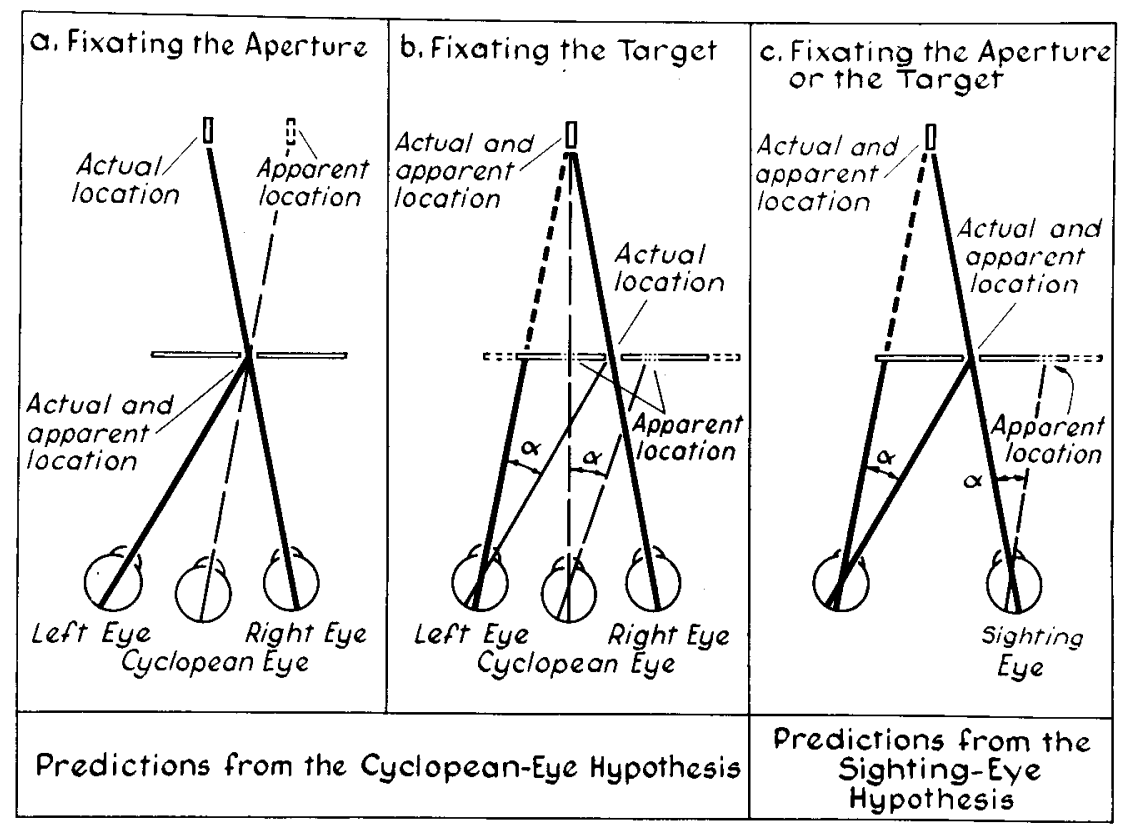

Figure 1. The predicted apparent locations of the aperture and the target. The predictions were determined under the assumption that the distances of the stimuli are correctly perceived. 
and the cyclopean eye. ${ }^{1}$ Specifically, Figure 1a shows that when a subject binocularly fixates the aperture, the aperture is correctly localized, whereas the target visible through the aperture appears displaced from its true position in the median plane. Figure $1 \mathrm{~b}$ shows that when both eyes are directed toward the target, the target is now correctly localized, but the aperture incorrectly appears in the median plane. In both figures, the stimuli appear on the line passing through the cyclopean eye and the intersection of the two visual axes.

Figure $1 \mathrm{c}$ illustrates the prediction of the sightingeye hypothesis, which has been described by Walls as follows: "One sights or points with one eye because the visual ego is as though located in one eye" (Walls, 1951, p. 404). Here it is shown that the fixated and nonfixated stimuli are both seen to be collinear with the sighting eye, and therefore the aperture and the target are both correctly localized regardless of which is being fixated. The apparent locations of the stimuli are not affected by the angular position of the nonsighting eye, because the line passing through the intersections of the two visual axes and the sighting eye is the same for the two fixations.

Figures $1 \mathrm{~b}$ and $1 \mathrm{c}$ also show another apparent location of the aperture, the location of the accompanying double image that should be seen. (Through this apparent aperture, the target is not seen.) The aperture should be seen as double when a subject's eyes are directed toward the target, because its images fall on noncorresponding points of the retinas. The depicted location is based on the principle of visual direction that states: the visual angle subtended by the two stimuli (the aperture and the target) will be projected to the center of visual direction; that is, the visual angle $(\alpha)$ at the nodal point of the eyes "transfers" to the location of the center of visual direction. We asked the subjects to indicate the apparent location of the aperture without mentioning the possible diplopia. In most cases, subjects did not report diplopia spontaneously but confirmed it when its presence was pointed out after the experiment. All subjects reported that they indicated the apparent location of the aperture through which the target was seen. Therefore, this second apparent location of the aperture shown in Figures $1 \mathrm{~b}$ and $1 \mathrm{c}$ will not be considered further in this paper. ${ }^{2}$

\section{Method}

Subjects. Twelve university students were selected; six were right- and six were left-eye sighters.

Apparatus and Stimuli. The target was an aluminum rod $1 \mathrm{~cm}$ in diameter and $13 \mathrm{~cm}$ in length. It was oriented vertically in the subject's median plane, $50 \mathrm{~cm}$ from the eyes. The card was $13 \times$ $11.5 \mathrm{~cm}$, was painted flat black, and had a $.6-\mathrm{cm}$ aperture in its center. It was mounted in a holder on a track $25 \mathrm{~cm}$ from the eyes, so that it could be moved readily left and right. The stimuli were mounted on a table. The subject's eyes and the aperture in the card were $10 \mathrm{~cm}$ above the table top. On the underside of this table were grooves 25 and $50 \mathrm{~cm}$ from the eyes. A measuring rod with a handle attached slid in each groove; the handles were positioned by the subject to indicate the apparent locations of the stimuli. The subject sat at the table with his/her head positioned by a chinrest.

Procedure. Before the start of the experiment, the sighting eye was determined with the usual procedure for the Card test. The subject was asked to hold the card with both hands in front and out of view, and then, on request, to bring it into view and to position it so that the target could be seen through the aperture.

In the experiment, the apparent location of the aperture was determined when the subject (1) fixated the aperture and (2) fixated the target seen through the aperture. The apparent location of the target was determined when the subject (3) fixated it through the aperture, (4) fixated the aperture, and (5) fixated it binocularly without the card in place. This latter viewing condition was used because it was expected that, when the target was fixated through the aperture, the target's position would be influenced by phoria (see Ono \& Weber, 1981). ${ }^{3}$ The subject indicated the apparent location of each stimulus by setting the position of the appropriate rod handle. When requested to fixate the aperture, the subject was instructed to fixate the center of its lower edge.

A trial consisted of two consecutive judgments of apparent location within a single viewing condition, and each of the five viewing conditions was presented in four different trials. The order of the $\mathbf{2 0}$ trials was randomized. The hand used to indicate the apparent location of a given stimulus was randomly determined, with the restriction that each hand be used equally often within each viewing condition.

\section{Results and Discussion}

Each response indicating apparent location was expressed as a displacement in centimeters from the objective median plane. A deviation to the subject's right was designated positive, and to the left, negative. The mean apparent locations, their $95 \%$ confidence intervals, and the predicted locations are shown in Table 1. The apparent locations of the fixated aperture and the fixated target were close to their veridical locations, in agreement with the predictions from the two hypotheses. The veridical location of the target was in the median plane for all subjects. The veridical location of the aperture varied slightly among subjects because of individual differences in interocular

Table 1

Predicted and Obtained Mean Apparent Locations of the Stimuli Expressed in Deviations (in Centimeters) From the Median Plane (Experiment 1)

\begin{tabular}{|c|c|c|c|c|c|}
\hline \multirow[b]{2}{*}{ Stimulus } & \multirow[b]{2}{*}{ Irixation } & \multicolumn{2}{|c|}{ Predicted } & \multicolumn{2}{|r|}{ Obtained } \\
\hline & & $\mathrm{SF}$ & C.E & Mean & $\mathrm{CI}$ \\
\hline \multicolumn{6}{|c|}{ Sighting Eye: Right } \\
\hline Aperture & $\begin{array}{l}\text { Aperture } \\
\text { Target }\end{array}$ & $\begin{array}{l}+1.50 \\
+1.50\end{array}$ & $\begin{array}{r}+1.50 \\
.00\end{array}$ & $\begin{array}{r}+1.09 \\
-.18\end{array}$ & $\begin{array}{r}-.40 \text { to }+2.58 \\
-1.70 \text { to }+1.34\end{array}$ \\
\hline Target & $\begin{array}{l}\text { Aperture } \\
\text { Target }\end{array}$ & $\begin{array}{l}.00 \\
.00\end{array}$ & $\begin{array}{r}+3.00 \\
.00\end{array}$ & $\begin{array}{r}+2.25 \\
-.13\end{array}$ & $\begin{array}{r}-.83 \text { to }+5.35 \\
-3.70 \text { to }+3.44\end{array}$ \\
\hline \multicolumn{6}{|c|}{ Sighting Lye: Left } \\
\hline Aperture & $\begin{array}{l}\text { Aperture } \\
\text { Target }\end{array}$ & $\begin{array}{l}-1.56 \\
-1.56\end{array}$ & $\begin{array}{r}-1.56 \\
.00\end{array}$ & $\begin{array}{r}-1.42 \\
-.01\end{array}$ & $\begin{array}{r}-.44 \text { to }-2.40 \\
-1.22 \text { to }+1.20\end{array}$ \\
\hline Target & $\begin{array}{l}\text { Aperture } \\
\text { Target }\end{array}$ & $\begin{array}{l}.00 \\
.00\end{array}$ & $\begin{array}{r}-3.12 \\
.00\end{array}$ & $\begin{array}{r}-2.18 \\
+.74\end{array}$ & $\begin{array}{r}-4.42 \text { to }+.06 \\
-.88 \text { to }+2.36\end{array}$ \\
\hline
\end{tabular}

Note-SE corresponds to the sighting-ele hypothesis, and CE to the cyclopean-cy hypothesis. $C I=95 \%$ confidence interval. 
distances. The mean veridical locations (and standard deviations) were $+1.50(.07)$ and $-1.56(.07)$ for the right- and left-sighting-eye subjects. In contrast, the mean apparent locations of the two stimuli, when not fixated, deviated from veridicality. In all four cases, they were closer to those predicted from the cyclopean-eye hypothesis than to those predicted from the sighting-eye hypothesis.

Two statistical analyses were performed. The first analysis directly examined the predicted and obtained values for the right- and left-sighting-eye groups separately, as shown in Table 1 . The second analysis examined the predicted and obtained values for the combined groups (i.e., right- and left-sighting-eye groups).

The first analysis was concerned with two sets of predictions that differed for the two hypotheses. The mean apparent location of the aperture while the target was being fixated was very close to the mean value predicted by the cyclopean-eye hypothesis for the right- and left-sighting-eye groups. These predicted values were contained in the corresponding $95 \%$ confidence intervals. However, the predicted values from the sighting-eye hypothesis were not contained within these intervals. The mean apparent location of the target when the aperture was being fixated was to the right of the actual location for rightsighting-eye subjects and to the left for left-sightingeye subjects. However, because the predicted values from both hypotheses were contained in the corresponding $95 \%$ confidence intervals, these results were somewhat ambiguous. This ambiguity was removed by narrowing the confidence interval in two

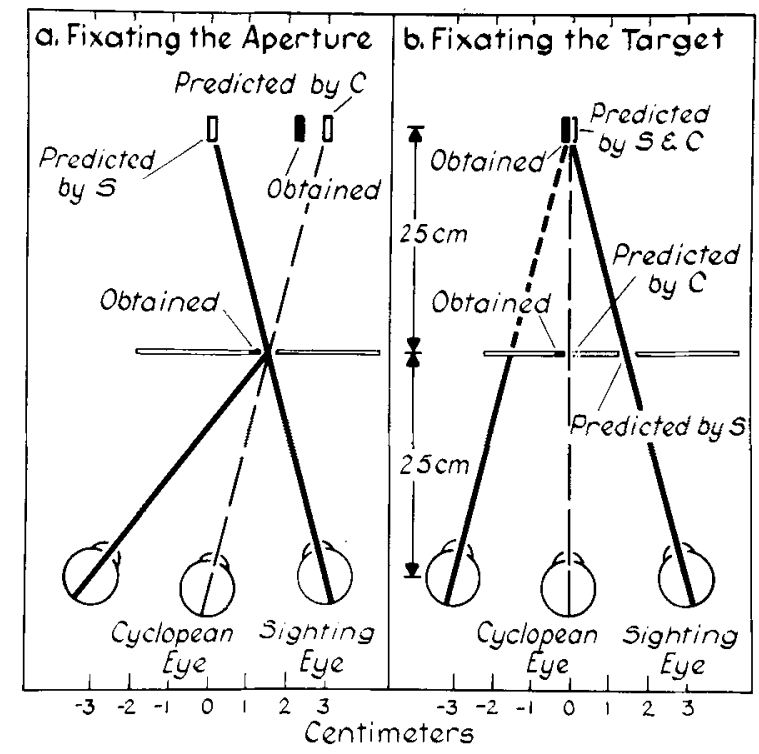

Figure 2. Mean apparent locations of the aperture and the target relative to the predicted apparent locations. A predicted location from the cyclopean-eye hypothesis is indicated by $C$, and a predicted location from the sighting-dominance test is indicated by $\mathbf{S}$. different ways: by combining the data from the two groups as described below, and by increasing the precision of the measurement in Experiment 3.

The composite results of all subjects (the signs of the apparent locations from left-sighting-eye subjects were reversed) and the locations predicted by the two hypotheses are shown in Figure 2. Interval estimations were performed on the combined apparent locations, and the results of the analyses confirmed the impression from the figure that the data are not consistent with the sighting-eye hypothesis but are consistent with the cyclopean-eye hypothesis. The $95 \%$ confidence interval for the composite means is -.87 to +.71 for the apparent location of the aperture when the target is fixated, and +.66 to +3.78 for the target when the aperture is fixated. These two intervals contain the predictions ( 0 and 3.05 , respectively) from the cyclopean-eye hypothesis but not those (1.53 and 0 , respectively) from the sighting-eye hypothesis. Clearly, the data offer more support to the cyclopean-eye hypothesis than to the sighting-eye hypothesis.

\section{EXPERIMENT 2}

The basis of the claim that the sighting eye is the center of visual direction is that two stimuli judged to be in the same visual direction are objectively collinear with one eye. Without a distinction between objective and apparent location, this evidence can lead to this incorrect claim. With the exception of Walls (1951), proponents of the sighting-eye hypothesis have not made this distinction (e.g., Porac \& Coren, 1981, p. 196ff). Even Helmholtz (1910/ 1962 , p. 259) neglected this distinction and argued against the concept of the cyclopean eye (cf. Ono \& Angus, 1974). However, Wells (1792), Hering (1879/ 1942), and Le Conte (1881) long ago demonstrated that the stimuli in the visual axis of one eye appear in the common axis (or in the line passing through the cyclopean eye and the intersection of the two visual axes). The results of Experiment 1 confirmed this for the stimuli collinear with the sighting eye in a sightingdominance test. However, since both hypotheses also make predictions concerning stimuli aligned with the nonsighting eye, they can be further evaluated by examining the visual direction of the stimuli collinear with that eye. Before this examination was undertaken in Experiment 3, Experiment 2 was conducted to determine the frequency with which the nonsighting eye is used for sighting in a modified Card test. A high frequency would imply two different sighting-eye hypotheses. A high variability of the eye used would imply that (1) the eye that serves as the center of visual direction can change easily or (2) the same eye serves as the center, but errors in identifying it can occur easily. In this experiment, the sighting dominance test was 
modified by constraining the starting position, and thus the direction of movement of the card.

\begin{abstract}
Method
The same 12 subjects, apparatus, and stimuli were used.

A trial started with the aperture of the card positioned on its track $15 \mathrm{~cm}$ to one side of the median plane. The same instructions used to determine the sighting eye in Experiment 1 were given, except that the subject was asked to adjust the position of the card by sliding it slowly along its track. A trial consisted of one adjustment of the card. Each subject did four trials, and the starting position of the card was alternated from one trial to the next. The starting side of the first trial was counterbalanced across subjects.
\end{abstract}

\section{Results and Discussion}

The results were clear. When the card was moved from the left, subjects stopped the card so that the left eye viewed the target. When the card was moved from the right, they stopped the card so that the right eye viewed the target. Only two subjects' responses did not fit this description. When moving the card from the side of their nonsighting eye (as determined in Experiment 1), these subjects stopped the card briefly when their nonsighting eye was aligned with the aperture and the target but then moved the card on again so that their sighting eye could view the target. This occurred in two trials for one subject and in one trial for the other subject. When asked about these trials after the experiment, one subject could not give a reason for the additional adjustment of the card, but the other said the card was readjusted because things "did not look the same" as in Experiment 1 . On elaboration, this subject said that he decided the card should be positioned so that the diplopic images of the aperture would appear in the same position as in Experiment 1. These three exceptions constituted only $12.5 \%$ of the trials starting from the side of the nonsighting eye, or $6 \%$ of the total trials.

The results of Experiment 2 are consistent with those obtained by Hamburger (1943). He used a procedure similar to that of Experiment 2 and found $68 \%$ (151 of 221 ) of his subjects used either eye, as compared with the normally reported figure of fewer than $10 \%$ when the usual procedure of sighting dominance tests is followed (see, e.g., Lederer, 1961; Porac \& Coren, 1976). We found $91 \%$ (11 of 12) used either eye. This is not to suggest that the Card test is unreliable. In fact, as a psychometric instrument, its reliability is impressive (see, e.g., Miles, 1928, 1929; Porac \& Coren, 1976), but the results of Experiment 1 (and Experiment 3) indicate that the basis of its reliability is not due to the sighting eye's being the center of visual direction. See Barbeito $(1980,1981)$ for a hypothesis that accounts for the reliability of the Card test.

That subjects align stimuli with either eye does not in itself imply that the sighting eye is not the center of visual direction. It is possible, for example, that two stimuli aligned with the nonsighting eye would appear to be collinear with the sighting eye. This possibility was examined in Experiment 3, but, before proceeding, we must clarify the sighting-eye hypothesis with respect to the results of Experiment 2.

There are two possible interpretations of the results. One is suggested by the term "ambiocular," which refers to variability in which eye is used. This variability can be due to changes in the center of visual direction. We will refer to the possibility that either eye can serve as the center as the "either-eye" hypothesis. Another possibility is that our procedure introduced a confounding bias in the measurement of the sighting eye, that is, that the true eye was not measured as such on nearly half of the trials. We will refer to the possibility that the sighting eye always serves as the center as the "one-eye" hypothesis. The predictions from these two hypotheses together with those from the cyclopean-eye hypothesis were examined in Experiment 3.

\section{EXPERIMENT 3}

Three different stimulus configurations were used to test the three competing hypotheses. The first was identical to that of Experiments 1 and 2, in which the target was located in the median plane. This same configuration yielded ambiguous results in Experiment 1 for one analysis. It will be referred to as the sighting-test configuration. In the second stimulus arrangement, the target was positioned so that the subjects would place the aperture in the median plane to see the target. This arrangement was directly analogous to Hering's classic windowpane demonstration, which he used to illustrate the concept of the cyclopean eye. Specifically, the aperture corresponded to the marker on the windowpane, and the target, to the treetop or the chimney (see Figure 3). The second arrangement will be referred to as Hering's configuration. In the third stimulus arrangement, the targets were positioned as in Hering's configuration, but the position of the aperture was such that the target would be seen through the aperture when positioned directly in front of an eye. In these three stimulus arrangements, the visual directions of the target seen with the nonsighting eye and those seen with the sighting eye were determined while a subject fixated the aperture.

In this experiment, a simple rule for all predictions from the three hypotheses is that the target would be seen on the line passing through the hypothesized center of visual direction and the intersection of the visual axes-the aperture for this experiment. The cyclopean-eye hypothesis predicted a nonveridical visual direction of the target in all conditions, whereas the either-eye hypothesis predicted veridicality in all conditions. The one-eye hypothesis predicted veridicality when the sighting eye viewed the target, but not when the nonsighting eye viewed the target. Spe- 
cific predictions described below applied to the experimental condition in which the card was midway between the target and the eyes and in which the assumption was made that the distance of the target was correctly perceived.

The predictions in the sighting-test configuration will be discussed in reference to Figures 1 and 2 . The cyclopean-eye hypothesis predicted that the target would be seen directly in front of the viewing eye, collinearly with the actual location of the aperture and the cyclopean eye (Figure 1a and 2a). The eithereye hypothesis predicted that the target would be seen in the median plane whether the left or the right eye viewed the target (Figure 1c and 2a). The one-eye hypothesis predicted that the target would be seen in the median plane when viewed by the sighting eye but not when viewed by the nonsighting eye. The predicted visual direction of the target viewed with the nonsighting eye was on the extension of the line passing through the nonlabeled eye and the aperture in Figure 1c, if the nonlabeled eye is the sighting eye. The target should be seen on the temporal side of the other eye, and the extent of nonveridicality in the frontoparallel plane should be equal to the interocular distance in our stimulus arrangement.

For Hering's configuration, the cyclopean-eye hypothesis predicted that the target seen with either eye should be seen in the median plane. The eithereye hypothesis predicted that the target seen with the left eye would be directly in front of the right eye and vice versa. The one-eye hypothesis predicted that the target seen with either eye would be seen directly in front of the nonsighting eye. (Predictions for the other stimulus configurations will not be elaborated here, but can be easily determined by drawing a line through the hypothesized center of visual direction and the aperture. The predicted locations can be found in Table 2.)

\section{Method}

Although the purpose of Experiment 3 was to measure visual direction as in Experiment 1, there were two major changes made in the method. The first was designed to decrease the variability of responses. Because apparent location determined by a subject using a visual criterion has smaller variability than that using a kinesthetic criterion (see Barbeito \& Ono, 1979; Ono \& Weber, 1981), the subject was not asked to point to the apparent location as in Experiment 1. Instead, the subject was asked to remember the apparent location of the monocularly viewed target and soon after to adjust a bifoveated stimulus to the remembered location. The second change was to ensure that the subject fixated the aperture. Maintaining the fixation that was required in this experiment (as in Experiment 1) is a difficult task, because it requires processing the visual direction of an object not fixated-a task seldom performed in everyday life and one that produces a tendency to change fixation. Consequently, a second experimenter watched the subject's eyes, and the trials in which the eyes moved before setting the apparent location were discarded. This procedure does not ensure that the aperture is being fixated, but does detect changes in fixation to the target. (See Ono \& Angus, 1974, for a discussion of this procedure.)
Subjects. Twelve members of the university community were selected, six with right- and six with left-sighting eyes. Two of these had participated in Experiments 1 and 2.

Apparatus and Stimuli. The following modifications were made to the apparatus and stimuli used in the two previous experiments. The target was a flat black rod $.3 \mathrm{~cm}$ in diameter and $11 \mathrm{~cm}$ high. A pulley permitted the subject to adjust the position of the target left or right in a frontal plane $50 \mathrm{~cm}$ from his/her eyes. A flat black screen, $5 \mathrm{~cm}$ high, which extended in the frontal plane in the subject's field of view, was positioned $25 \mathrm{~cm}$ from the subject's eyes. This screen restricted the view of the target to its upper half and acted as a guide for the adjustment of the card, so that the aperture's distance from the eyes would be constant across subjects. The card was a $25 \times 17.5 \mathrm{~cm}$ piece of white cardboard with a $.6-\mathrm{cm}$ aperture. As an aid to fixation, cross hairs were positioned within the aperture.

Procedure. As in Experiment 1, the sighting eye of each subject was determined with the Card test. The subject was then positioned at the apparatus. The task for the subject was first to position the card by moving it slowly from one side of the field of view until the target could be seen through the aperture. The subject then fixated the cross hairs and noted the apparent direction of the target. On command, the card was quickly moved out of view, during which time the experimenter moved the target to a new position. Finally, the subject bifoveated the target and adjusted its position, using the pulley, to match the direction in which it appeared when fixating the cross hairs.

Three positions of the target were used: $+3,0$, and $-3 \mathrm{~cm}$. The two outside locations were approximations of positions straight ahead of the eye. Given that the subject's head was not fixed with a bite-board, precise settings of the stimuli relative to the eyes were not possible. A trial consisted of one adjustment of the card and the subsequent setting of the target for a given target position. For each subject, there were 12 trials for each target position: six with the card's starting position to the left and six to the right.

Trials were done in pairs involving the same target position and two starting sides of the card. For each subject, one of the six possible orders of the target positions was used, with each of the possible orders being followed by two subjects. The starting side of the card was alternated on trial pairs, and the side of the adjustment for the first trial pair was counterbalanced across subjects.

Each subject did four practice trials. Care was taken to prevent the subject from seeing the target between trials by having the starting position of the card block the subject's view until the aperture, target, and eye moved into alignment. The subject did not move the card beyond this point during the experiment; that is, the subject viewed the target with the eye intended by the experimenter in all trials. (Thus, the finding of Experiment 2 was replicated.)

\section{Results and Discussion}

Each response indicating apparent location was expressed in the same way as in Experiment 1: the median plane with zero, the left of it with a negative value, and the right of it with a positive value. The means and their $95 \%$ confidence intervals for the apparent locations are shown in Table 2, along with the predicted values from the three hypotheses. To compute the predicted values, the mean interocular distances for the two groups were used: 6.05 and 6.10 for the right- and left-sighting-eye subjects, respectively. As expected from the change in the procedure, the confidence intervals are considerably smaller than those found in Experiment 1.

In the sighting-test configuration, regardless of the eye used by the two groups of subjects, the apparent 
location of the target was in front of the viewing eye. This is the outcome predicted by the cyclopean-eye hypothesis. These results remove the ambiguity from the first analysis of the results in Experiment 1. The results of this experiment, with the more precise measurement of apparent location, are clearly inconsistent with the either-eye and the one-eye hypotheses, because their predicted values are not contained in the respective confidence intervals (shown in Table 2).

In Hering's configuration, the two visual axes intersect at the aperture near the median plane, and, according to the cyclopean-eye hypothesis, the target should be seen near the median plane. (The axes did not intersect exactly at the median plane because the target's location was fixed for all subjects and because we did not make adjustments for individual differences in interocular distances.) The obtained apparent locations of the target agree well with this prediction, and the four confidence intervals, shown in Table 2, do not contain any of the predicted values from the either-eye and one-eye hypotheses. Figure 3 depicts the results for all subjects, and also shows Hering's demonstration and the actual stimulus arrangement superimposed on the results. This figure is provided to emphasize that the visual directions of the stimuli in the sighting-dominance test are essentially the same as those for the classic demonstration.

In the other configurations, the same conclusion holds. The $95 \%$ confidence intervals of the obtained means contained the predicted values from the cyclopean-eye hypothesis but not those from the other hypotheses.

Consider together the results from all three stimulus configurations, as presented in Table 2 . Not one

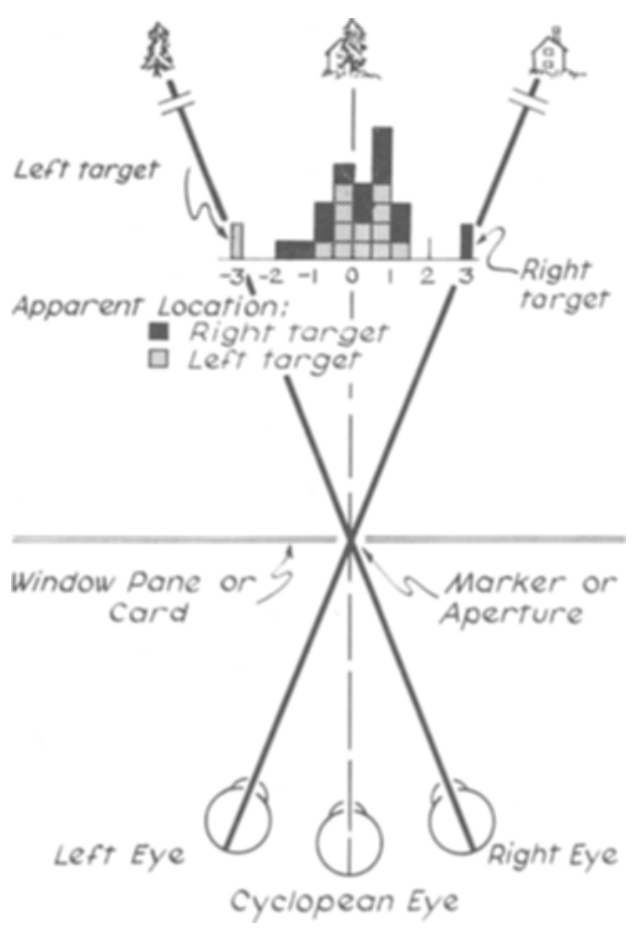

Figure 3. Frequency histogram of the apparent locations of the stimuli in Hering's configuration. The relative positions of the stimuli and a schematic illustration of Hering's windowpane demonstration are also shown.

of the 12 confidence intervals contains the predicted values from the either-eye or the one-eye hypotheses. In contrast, all 12 contain the predicted values from the cyclopean-eye hypothesis. These results unequiv-

Table 2

Predicted and Obtained Mean Apparent Locations, Expressed in Deviations (in Centimeters) From the Median Plane, for the Three Stimulus Configurations (Experiment 3)

\begin{tabular}{|c|c|c|c|c|c|c|c|}
\hline \multirow{2}{*}{$\begin{array}{l}\text { Sighting } \\
\text { Eye }\end{array}$} & \multirow{2}{*}{$\begin{array}{l}\text { Stimulus } \\
\text { Location }\end{array}$} & \multirow{2}{*}{$\begin{array}{c}\text { Viewing } \\
\text { Eye }\end{array}$} & \multicolumn{3}{|c|}{ Predicted } & \multicolumn{2}{|c|}{ Obtained } \\
\hline & & & EE & $\mathrm{OE}$ & $\mathrm{CE}$ & Mean & CI \\
\hline \multicolumn{8}{|c|}{ Sighting Test Configuration } \\
\hline Right & 0 & $\begin{array}{l}\text { Right } \\
\text { Left }\end{array}$ & $\begin{array}{l}0 \\
0\end{array}$ & $\begin{array}{r}.00 \\
-6.05\end{array}$ & $\begin{array}{l}+3.03 \\
-3.03\end{array}$ & $\begin{array}{l}+3.56 \\
-3.43\end{array}$ & $\begin{array}{l}+2.58 \text { to }+4.54 \\
-2.76 \text { to }-4.10\end{array}$ \\
\hline Left & 0 & $\begin{array}{l}\text { Right } \\
\text { Left }\end{array}$ & $\begin{array}{l}0 \\
0\end{array}$ & $\begin{array}{r}+6.10 \\
.00\end{array}$ & $\begin{array}{l}+3.05 \\
-3.05\end{array}$ & $\begin{array}{l}+3.68 \\
-2.20\end{array}$ & $\begin{array}{l}+2.88 \text { to }+4.48 \\
-1.20 \text { to }-3.20\end{array}$ \\
\hline \multicolumn{8}{|c|}{ Hering's Configuration } \\
\hline Right & $\begin{array}{l}-3 \\
+3\end{array}$ & $\begin{array}{l}\text { Right } \\
\text { Left }\end{array}$ & $\begin{array}{l}-3 \\
+3\end{array}$ & $\begin{array}{l}-3.00 \\
-3.05\end{array}$ & $\begin{array}{l}+.03 \\
-.03\end{array}$ & $\begin{array}{l}+.32 \\
-.38\end{array}$ & $\begin{array}{r}-.48 \text { to }+1.12 \\
-1.36 \text { to }+.60\end{array}$ \\
\hline Left & $\begin{array}{l}-3 \\
+3\end{array}$ & $\begin{array}{l}\text { Right } \\
\text { Left }\end{array}$ & $\begin{array}{l}-3 \\
+3\end{array}$ & $\begin{array}{l}+3.10 \\
+3.00\end{array}$ & $\begin{array}{l}+.05 \\
-.05\end{array}$ & $\begin{array}{l}+.22 \\
+.43\end{array}$ & $\begin{array}{l}-.29 \text { to }+.73 \\
-.34 \text { to }+1.20\end{array}$ \\
\hline \multicolumn{8}{|c|}{ Other Configurations } \\
\hline Right & $\begin{array}{l}+3 \\
-3\end{array}$ & $\begin{array}{l}\text { Right } \\
\text { Left }\end{array}$ & $\begin{array}{l}+3 \\
-3\end{array}$ & $\begin{array}{l}+3.00 \\
-9.05\end{array}$ & $\begin{array}{l}+6.03 \\
-6.03\end{array}$ & $\begin{array}{l}+5.90 \\
-6.22\end{array}$ & $\begin{array}{l}+4.80 \text { to }+7.00 \\
-5.27 \text { to }-7.17\end{array}$ \\
\hline Left & $\begin{array}{l}+3 \\
-3\end{array}$ & $\begin{array}{l}\text { Right } \\
\text { Left }\end{array}$ & $\begin{array}{l}+3 \\
-3\end{array}$ & $\begin{array}{l}+9.10 \\
-3.10\end{array}$ & $\begin{array}{l}+6.05 \\
-6.05\end{array}$ & $\begin{array}{l}+6.25 \\
-5.13\end{array}$ & $\begin{array}{l}+5.58 \text { to }+6.92 \\
-4.13 \text { to }-6.13\end{array}$ \\
\hline
\end{tabular}

Note-EE corresponds to the either-eye hypothesis, $O E$ to the one-eye hypothesis, and $C E$ to the cyclopean-eye hypothesis. $C I=95 \%$ confidence interval. 
ocally support the cyclopean-eye hypothesis and are inconsistent with the other hypotheses.

In spite of this support for the cyclopean-eye hypothesis, we speculate that, given a more precise measurement of visual direction and/or a larger sample size, the predictions of the cyclopean-eye hypothesis also would fail (in fact, two predicted values came close to not being contained by their respective confidence intervals). This expectation is based on the fact that the hypothesis stated in this paper is a simplification. There are nonrandom individual differences in the location of the cyclopean eye (e.g., Barbeito, 1981), and predictions based on the measured location of the cyclopean eye would differ from those in Tables 1 or 2. Therefore, if one obtains even smaller confidence intervals, it is likely that the "simple" predicted values would not be contained within them.

\section{GENERAL DISCUSSION}

The results of this study support the cyclopeaneye hypothesis and, at the same time, raise serious doubts about the viability of the sighting-eye hypothesis. Thus, despite the amount of attention the sighting eye has received in the literature, its theoretical significance for vision has yet to be established. Whatever the significance of the sighting eye, this study makes it clear that the eye preferred for sighting in the Card test is not the center of visual direction. The center is located between the two eyes.

Despite our results, we do not fault Walls (1951) on his logic. He reported no apparent movement of two stimuli collinear with the sighting eye during rotation of the nonsighting eye, but did report movement of the stimuli collinear with the nonsighting eye during rotation of the sighting eye. Given these data, one must conclude that the center of visual direction is located in the sighting eye. We question the generalizability of his data. Walls does not state the population from which his subject(s) were drawn, and therefore his hypothesis may be based on the results from unique subject(s) to whom the hypothesis applied and thus should not be generalized to the whole population. In our four studies in which the location of the cyclopean eye was measured (Barbeito, 1981; Barbeito \& Ono, 1979; Mitson, Ono, \& Barbeito, 1976; Ono et al., 1972), all subjects were found to have the visual direction center between the eyes.

To investigators of binocular visual direction, the results of the present study should not be surprising. The stimuli for this experiment are essentially the same as those used by Hering $(1879 / 1942)$ to demonstrate the existence of the cyclopean eye, as we emphasized in Experiment 3. The stimuli are also essentially the same as those used in one method of measuring the location of the cyclopean eye. In Roelofs' (1959) method, the two ends of a tube are made col- linear with one eye and a subject is asked to indicate where on the face the tube appears to point. Subjects report that the tube appears to point between the two eyes (Roelofs, 1959). Moreover, this finding has been confirmed by more recent studies that used variations of Roelofs's method (Barbeito \& Ono, 1979; Mitson et al., 1976). What is surprising, however, is that the sighting-eye hypothesis persists (Porac \& Coren, 1981). Whatever the reason for the persistence, the stimuli used in this study should counter any argument that the cyclopean-eye hypothesis applies only to special laboratory conditions and not to the setting of a sighting test.

The lack of impact of the visual direction studies on ocular dominance research is likely related to the high reliability of sighting-dominance tests. This high reliability suggests that the sighting eye serves some visual function. Its possible function as the center of visual direction follows a slight and seemingly insignificant shift in thinking from "we see with our eyes" to "we see from an eye." Indeed, if the locations of stimuli at different distances are seen correctly without moving our eyes, the sighting-eye hypothesis must be considered viable. However, one consequence of the cyclopean eye's being the center for visual direction is that at least one of the apparent locations of two stimuli aligned with one eye will be nonveridical. Why such percepts are not compelling in our day-to-day experience cannot be answered from the results of the study, but, as the results of Experiments 1 and 3 showed, the nonfixated stimulus is not seen in its correct location.

The nonveridicality described here should not be a problem in everyday life, however, because we can process the correct direction of a nonfixated object

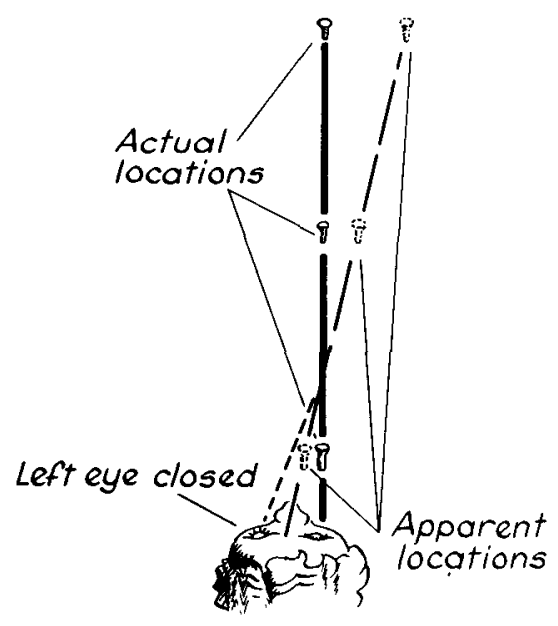

Figure 4. The actual and apparent locations of three nalls being checked for their alignment. The figure is drawn with the visual axis of the closed eye not directed toward a particular nail and with the assumption that the distances of the three nails are correctly perceived. 
by making an eye movement in order to bring the intersection of the two visual axes to the object despite its incorrectly perceived location (Ono \& Nakamizo, 1977). Furthermore, the nonveridicality of the apparent location is not important for checking the alignment of objects. For example, consider a person who sights along three nails to see if they are in line. The apparent locations of the three nails are diagrammed in Figure 4. The three nails will appear on the common axis (the line passing through the intersection of the two visual axes and the cyclopean eye), and at least two of the nails will not appear where they actually are. This is true even when the nonsighting eye is closed or occluded (see Ono \& Weber, 1981). In this illustration, all three nails are seen in nonveridical locations because the intersection of the visual axes is not on any of the stimuli. Note that the judgment of the alignment can be made from the "incorrectly" seen locations, that is, that perception is veridical in terms of collinearity but not in terms of locations. Hence, to check the alignment of the three nails, whether or not the nails are seen in their veridical locations, is immaterial.

In sum, wherever we see an object, we do not see it from our sighting eye. We see it from our cyclopean eye.

\section{REFERENCES}

BaRBeito, R. Ocular dominance: An explanation based on sighting behaviour. Doctoral dissertation, York University, Toronto, 1980.

BARBE1To, R. Sighting dominance: An explanation based on the processing of visual direction in tests of sighting dominance. Vision Research, 1981, 21, 855-860.

Barbeito, R., \& ONo, H. Four methods of locating the egocenter: A comparison of their predictive validities and reliabilities. Behavior Research Methods \& Instrumentation, 1979, 11, 31-36.

Channwoon, J. R. B. Observations on ocular dominance. Optician, $1949,118,85-88 ; 96$.

Charnwood, J. R. B. An essay on binocular vision. London: Hatton, 1965.

Coldinge, A. Changes in the position of the binoculus with unequal retinal illuminance. British Journal of Physiological Optics, 1979, 33, $42-54$.

Francis, J. L., \& Harwood, K. A. The variation of the projection centre with differential stimulus and its relation to ocular dominance. In Transactions of the International Ophthalmic Optical Congress. London: British Optical Association, 1951.

FRY, G. A. Visual perception of space. American Journal of Optometry, 1950, 27, 531-553.

Hamburger, F. A. Über monoculare Dominanz im binokularen Sehakt. Monatsblatter fur A ugenheilkunde, 1943, 109, 1-11.

HeLmholtz, H. von. [Handbook of physiological optics] (Vol. 3) (J. P. C. Southall, Ed. and trans.). New York: Dover, 1962. (Originally published, 1910).

HERING, E. [The theory of binocular vision] (B. Bridgeman and L. Stark, Eds. and trans.). New York: Plenum Press, 1977. (Originally published, 1868.)

Hering, E. [Spatial sense and movements of the eye] (C. A. Radde, trans.). Baltimore: American Academy of Optometry, 1942. (Originally published, 1879.)

Howard, I. P. Human visual orientation. Chichester, England: Wiley, 1982.
Le Conte, J. Sight: An exposition of the principles of monocular and binocular vision. New York: Appleton, 1881.

LEDERER, J. Ocular dominance. Australian Journal of Optometry, 1961, 44, 531-539; 570-574.

Mather, J. Visual direction and parameters of binocular space (Doctoral dissertation, Bryn Mawr College, 1969). Dissertation Abstracts International, 1971, 31, 4367B. (University Microfilms No. 71-383)

MiLes, W. R. Ocular dominance: Methods and results. Psychological Bulletin, 1928, 25, 155-156.

MILES, W. R. Ocular dominance demonstrated by unconscious sighting. Journal of Experimental Psychology, 1929, 12, 113-126.

Mitson, G. L., Ono, H., \& Bargeito, R. Three methods of measuring the location of the egocentre: Their reliability, comparative locations and intercorrelations. Canadian Journal of Psychology, 1976, 30, 1-9.

OGLE, K. N. Ocular dominance and binocular retinal rivalry. In H. Davson (Ed.), The eye (Vol. 4). New York: Academic Press, 1962.

Ono, H. Axiomatic summary and deductions from Hering's principles of visual direction. Perception \& Psychophysics, 1979 , 25, 473-477.

Ono, H. On Wells's (1972) law of visual direction. Perception \& Psychophysics, 1981, 30, 403-406.

ONo, H., \& Angus, R. G. Adaptation to sensory-motor conflict produced by the visual direction of the hand specified from the cyclopean eye. Journal of Experimental Psychology, 1974, 103, $1-9$.

Ono, H., \& NaKamizo, S. Saccadic eye movements during changes in fixation to stimuli at different distances. Vision Research, 1977, 17, 233-238.

Ono, H., \& Weben, E. Nonveridical visual direction produced by monocular viewing. Journal of Experimental Psychology: Human Perception and Performance, 1981, 7, 937-947.

Ono, H., Wilkinson, A., Muter, P., \& Mrtson, L. Apparent movement and change in perceived location of a stimulus produced by a change in accommodative vergence. Perception \& Psychophysics, 1972, 12, 187-192.

PArson, B. S. Lefthandedness. New York: Macmillan, 1924.

Pickwell, L. D. Hering's law of equal innervation and the position of the binoculus. Vision Research, 1972, 12, 1499-1507.

Porac, C., \& Coren, S. Lateral preferences and human behavior. New York: Springer-Verlag, 1981.

Porac, C., \& Coren, S. The dominant eye. Psychological Bulletin, $1976,83,880-897$.

Roesors, C. O. Considerations on the visual egocentre. Acta Psychologica, 1959, 16, 226-234.

Rubin, M. L., \& Walls, G. L. Fundamentals of visual science. Springfield, Ill: Charles C Thomas, 1969.

ShEARD, C. Unilateral sighting and ocular dominance. American Journal of Physiological Optics, 1926, 7, 558-567.

Walls, G. L. A theory of ocular dominance. A.M.A. Archives of Ophthalmology, 1951, 45, 387-412.

WELL, W. C. An essay upon single vision with two eyes; together with experiments and observations on several other subjects in optics. London: T. Cadell, 1792. (The original reference may be difficult to find, but Wells's propositions and his experimental results concerning apparent location of a stimulus are discussed in Ono, 1981).

\section{NOTES}

1. Attempts to measure the location of the visual direction center (e.g., Barbeito \& Ono, 1979; Mather, 1969; Mitson, Ono, $\&$ Barbeito, 1976) have shown that there are individual differences in its location. However, because the measured locations are usually in the vicinity of the median plane, the use of the assumed location will suffice for the purpose of contrasting the predictions of the cyclopean- and the sighting-eye hypotheses. 
2. Strictly speaking, the predictions illustrated in the figure are not restricted to the eye positions shown. As long as the convergence angle remains the same in each panel as in Figure 1, the predictions will remain the same. To elaborate, imagine that the two eyes moved $5 \mathrm{deg}$ to the right. The stimuli that were on the visual axes would now be $5 \mathrm{deg}$ away from the new position of the visual axes. Therefore, they would be seen $5 \mathrm{deg}$ away from the new positions of the common axis.

3. We expected a mean difference of about $.8 \mathrm{~cm}$ between these latter two conditions because of phoria in the nonsighting eye (see Ono \& Weber, 1981), but the mean location of the target was approximately the same whether subjects fixated on the target monocularly through the aperture or binocularly without the card. Therefore, we will not consider further this condition.

(Manuscript received December 30, 1981; revision accepted for publication May 19, 1982.) 